\title{
Energy Scavenging - an Introductory Engineering Project
}

\section{Dr. S. Scott Moor, Indiana University Purdue University, Fort Wayne}

Scott Moor is an Associate Professor of engineering and Coordinator of First-year Engineering at Indiana University-Purdue University, Fort Wayne. He received a B.S. and M.S. in chemical engineering from MIT. After more than a decade in industry, he returned to academia at the University of California, Berkeley, where he received a Ph.D. in chemical engineering and an M.A. in statistics. He is a registered Professional Chemical Engineer in California. His research interests include engineering education with an emphasis on developing and testing educational materials and learning spaces that stimulate serious play.

\section{Mr. Stephen Heindel, Indiana University-Purdue University Fort Wayne}

Stephen Heindel is pursuing a Bachelors of Science in Computer Engineering with a minor in Computer Science and Mathematics at Indiana University-Purdue University Fort Wayne (IPFW). Stephen has been the Teaching Assistant for the introductory engineering course at IPFW since the Spring semester of 2012. $\mathrm{He}$ has been actively involved in new student outreach events for the engineering department.

Dr. Yanfei Liu, Indiana University Purdue University, Fort Wayne 


\section{Energy Scavenging - an Introductory Engineering Project}

\section{Introduction}

First year engineering courses come with a wide range of objectives and configurations. However, it is quite common that they include a hands-on project of some kind. A recent workin-progress attempting to develop a taxonomy for first-year engineering programs has noted four overarching possible categories for what is covered in these courses: 1) professional skills (e.g., teamwork, communication), 2) engineering skills (e.g., mathematics, programing, graphics), 3) orientation to the engineering profession and 4) orientation to the particular university/program (including student success topics). ${ }^{1}$ A well designed project can potentially contribute to several or even all of these overall areas.

Such a project in a general first-year engineering course should be engaging, contemporary and sufficiently broad so as to address multiple facets of engineering including multiple engineering topics and important soft-skills. The project needs to be challenging while being understood by the typical student.

An energy scavenging project that incorporates multiple facets of engineering in one project has been refined over several years. The project consists of designing a mechanical system that harnesses the power of a motor to vibrate piezoelectric buzzer creating an electrical current. ${ }^{2}$ The output current is rectified and used to charge a micro-battery. The key goals for this project are that it:

1. is engaging to students, providing motivation for the active study of engineering,

2. exposes students to key engineering skills and habits, beginning to develop disciplined problem solving approaches,

3. illustrates multiple engineering topics from a range of engineering disciplines, helping to introduce them to the program/profession and aiding with finalization of their selection of major.

4. is practical to implement.

This project addresses aspects of all four categories mentioned earlier. It is conducted as a structured team project that allows an introduction to professional skills including project process, teamwork and communication. The project requires the use of a range of engineering skills including design, experimentation, data analysis and graphing. It provides an introduction to the different areas within engineering by including the mechanical design of a system to vibrate a piezoelectric device and the electrical conditioning and analysis of the piezoelectric output. In addition, students discover how engineers approach a project. Orientation to the program is covered in supplemental lecture material that addresses the specific majors in our program and how future course work relates to what students are seeing in the project.

\section{Context \& Overview}

This project is used in a one-credit Introduction to Engineering class that is the beginning of a multiple course first-year sequence. Additional courses emphasize specific engineering skills including graphics and computer tools. They are in the engineering program of a regional state 
university. Students can complete degrees in Civil, Mechanical, Electrical or Computer engineering. Some students transfer to the state's major land-grant university usually to complete other engineering majors. Admission is nearly open allowing most students who have the mathematics prerequisites to enter the program. Because of this open admission the students in the course come in with an extremely wide range of backgrounds and abilities.

This energy-harvesting project has been used in various forms since 2009 and evolved over that time. The initial project was discussed previously. ${ }^{3}$ This paper focuses of specific revisions to the project in recent years. These revisions include:

1. a change in the project process that allows improved scaffolding to support student progress and

2. the development of a sound-card signal analyzer in MATLAB® and an associated charging duty cycle estimate that helps guide students to make better design choices (another form of scaffolding).

The subsequent sections of the paper will examine key background on instructional practices, the overall project process used to scaffold student work, details on the design of the MATLAB sound card signal analyzer including a key duty cycle measurement, performance of the signal analyzer, and assessment of the overall project.

\section{Instructional Practices}

Many studies note the needs of engineering students to develop a broader more flexible expertise. A recent literature survey by Litzinger, et. al. reviews instructional practices that support the development of expertise. ${ }^{4}$ They list practices in three categories affective, metacognitive and cognitive. For first-year students it is critical to address this affective (motivational) area. In this paper three practices are listed for this area:

1. "Arouse interest for students of contrasting abilities and goals"

2. "Provide stimulating, interesting and varied assignments that are within the range of students' abilities but challenge them to reach for the top of that range" and

3. "Make connections to students' interests and intended careers."4

In addition to key preparation for engineering practice, these three practices are also key for motivating students and preparing them for the rigors of studying engineering.

The project described in this paper is designed to utilize these three approaches. The topic of energy harvesting from ambient renewable sources is very contemporary and of interest to most beginning engineering students. The hands on nature of the project and use of LEGOßS are also appealing to students. The project is conducted over six weeks using both in and out of class activities. The diversity of topics, activities and settings utilized in this project helps interest students with a wide range of background experiences and career goals.

The project activities include conceptual design of a mechanical system, hands on implementation of that system, experimentation with chosen design, use of electrical equipment (power supply, bread board, simple signal analyzer, and voltmeter) and analysis of the results. These varied assignments address the second practice above. In addition, staging activities over six weeks and beginning new activities in class helps insure that assignments will be within students' range of abilities. 
Throughout the project class time is used to explain and connect the various project activities to students' possible majors and career interests. The mechanics, circuits and test equipment used in the project provide natural starting points for introductions to Mechanical and Electrical Engineering. Our other majors are introduced via the discussion of the applications of energy harvesting - Civil Engineering is introduced with topics such as remote signage and smart structures; Computer engineering is introduced with embedded systems that control or utilize energy harvesting. This addresses the third practice listed.

This project is also informed by instructional practices from the other areas listed in the paper as well. In the cognitive area one of the key practices is to "Provide support to "scaffold" student learning, especially for assignments that require integration of knowledge and skills." 4 The improvements to the project covered in this paper (i.e., revised project process and custom programed computer instrumentation) are primarily focused on helping to scaffold students understanding of the project and allow them to make better decisions about their designs. Again this is an approach that is particularly important to first-year students.

In addition to providing scaffolding, the project process also sets up a timeline that allows instructors to "Provide timely and constructive feedback on the learning processes so students understand what they know and can do well and what they need to improve." 4 This is accomplished via formal feedback on a series of there intermediate student reports and informally by feedback during class time for project work.

In discussing Litzinger, et. al. it is important to note that a key point of the paper is that these instructional strategies be implemented not just on a course-by-course basis but at the curricular level. It is crucial that projects such as this one in the first-year, be built on as students' progress through their majors.

\section{Project Process \& Scaffolding}

The project is organized into three phases to help scaffold the project as shown in Table 1. Each stage is two weeks long for this course that meets once per week. New concepts or techniques are introduced in each class and students are given a chance to try out the new techniques with the instructors support. Completing the full project development, measurement and documentation requires student teams meet between classes.

Table 1: Energy Scavenging Project Phases and Associated Tools

\begin{tabular}{|c|c|c|c|}
\hline Week & Phase & Deliverable & Tools Introduced \\
\hline 1 & \multirow{2}{*}{$\begin{array}{ll}\text { I. } & \begin{array}{l}\text { Mechanical } \\
\text { Design }\end{array} \\
\end{array}$} & Design Concepts Memo & \multirow[t]{2}{*}{ MLCad Software } \\
\hline 2 & & Design Implementation Memo & \\
\hline 3 & \multirow{2}{*}{$\begin{array}{l}\text { II. Mechanical } \\
\text { Construction \& } \\
\text { Testing }\end{array}$} & \multirow[b]{2}{*}{ Initial Measurements Memo } & \multirow{2}{*}{$\begin{array}{l}\text { Power Supply, } \\
\text { Optical Tachometer, } \\
\text { Voltage divider } \\
\text { MATLAB Signal Analyzer }\end{array}$} \\
\hline 4 & & & \\
\hline 5 & \multirow{2}{*}{$\begin{array}{l}\text { III. Electrical Circuit } \\
\text { and Final Testing }\end{array}$} & \multirow[b]{2}{*}{ Technical Memo } & \multirow{2}{*}{$\begin{array}{l}\text { Breadboard, } \\
\text { Multimeter }\end{array}$} \\
\hline 6 & & & \\
\hline
\end{tabular}


Table 1 lists the four memos that are submitted as the project deliverables. With each memo students must present a greater quantity and depth of material. The weight in the final grade also increases as the project progresses. The intermediate memos allow the instructor to give concrete feedback on each group's progress. A webpage is available with complete assignment memos and rubrics as well as links to other key resources. ${ }^{5}$

A quick review of the project phasing and the sound card oscilloscope with charging duty cycle estimate is included below to illustrate how these provide scaffolding to the project.

Phase I: Mechanical Design - In the first class students are introduced to the general concept of harvesting small quantities of energy from ambient sources (energy scavenging) and the particular idea of generating electricity from the vibration of a piezoelectric material. During the week each group is assigned the task of brainstorm multiple concepts for converting the rotational motion of a motor to vibration of a piezoelectric crystal. They are required to turn in a memo reviewing three general vibration design concepts. This initial activity is meant to be open ended and creative. Students are encouraged to think creatively and not given information that might limit their open-ended exploration. In addition, during this first class a drag and drop LEGO ${ }^{\circledR}$ CAD program ${ }^{6}$ is introduced and students are individually assigned to try out the drawing and produce a first drawing. This is intended to get them ready for the following week's project activity.

In the second class (one week later) the design concepts students have developed are discussed in class. Instructors guide this discussion to cover a range of options and discuss their potential advantages and disadvantages. Design concepts covered generally include a reverse train drive wheel type linkage, a ratchet type mechanism where the piezo housing bounces off the teeth of a gear, the use of a cam, an offset spinning weight (e.g. as in a phone vibrator or the rumble feedback of a game controller), or simply hitting the piezo housing. Students are then encouraged to review their concepts based on this discussion. Over the second week students are asked to develop two concepts in detail including how they would be implemented with the LEGO parts available in class. They present these designs in a memo using LEGO CAD drawings and a written description. Students are allowed to use their original concepts or to implement a new concept based on the class discussion.

This two-step process provides scaffolding to the student design process. It allows students to consider their own ideas for design (the first week) but then gives them a chance to take advantage of others ideas and the instructor's comments in order to develop a more successful design (the second week) resulting in more successful design. In addition in Atman, et. al.'s paper comparing students design process to the design process of experienced professional designers, they found that one of the key differences is the amount of time professionals spend in the project scope and definition phase. ${ }^{7}$ This two week process models for students the practice of spending more time up front defining and conceptualizing the problem. During these classes a design process from the course textbook is reviewed and compared to the project steps. ${ }^{8}$

Phase II: Mechanical Construction and Testing - In the second two-week phase students built their LEGO design (students have often begun this at the very end of the first phase), measure 
the rotational speeds, and test the electrical output signal from the piezoelectric buzzer. In the first week they learn to use a power supply to power their motor and an optical tachometer to measure the resulting rotational speed. In the second week the electrical output from the vibrating piezoelectric is measured with a sound card signal analyzer. This custom MATLAB program captures the input into a microphone port, the signal frequency is analyzed with a Fast Fourier Transform (FFT) and the charging capability estimated using a special duty cycle calculation. The first screen of this analyzer is shown in Figure 1. Because of the limited voltage range students are shown how to construct and use a simple resistance voltage divider. This divider uses a $1 \mathrm{kOhm}$ and a $19 \mathrm{kOhm}$ resistance to provide a 20:1 reduction in the voltage.

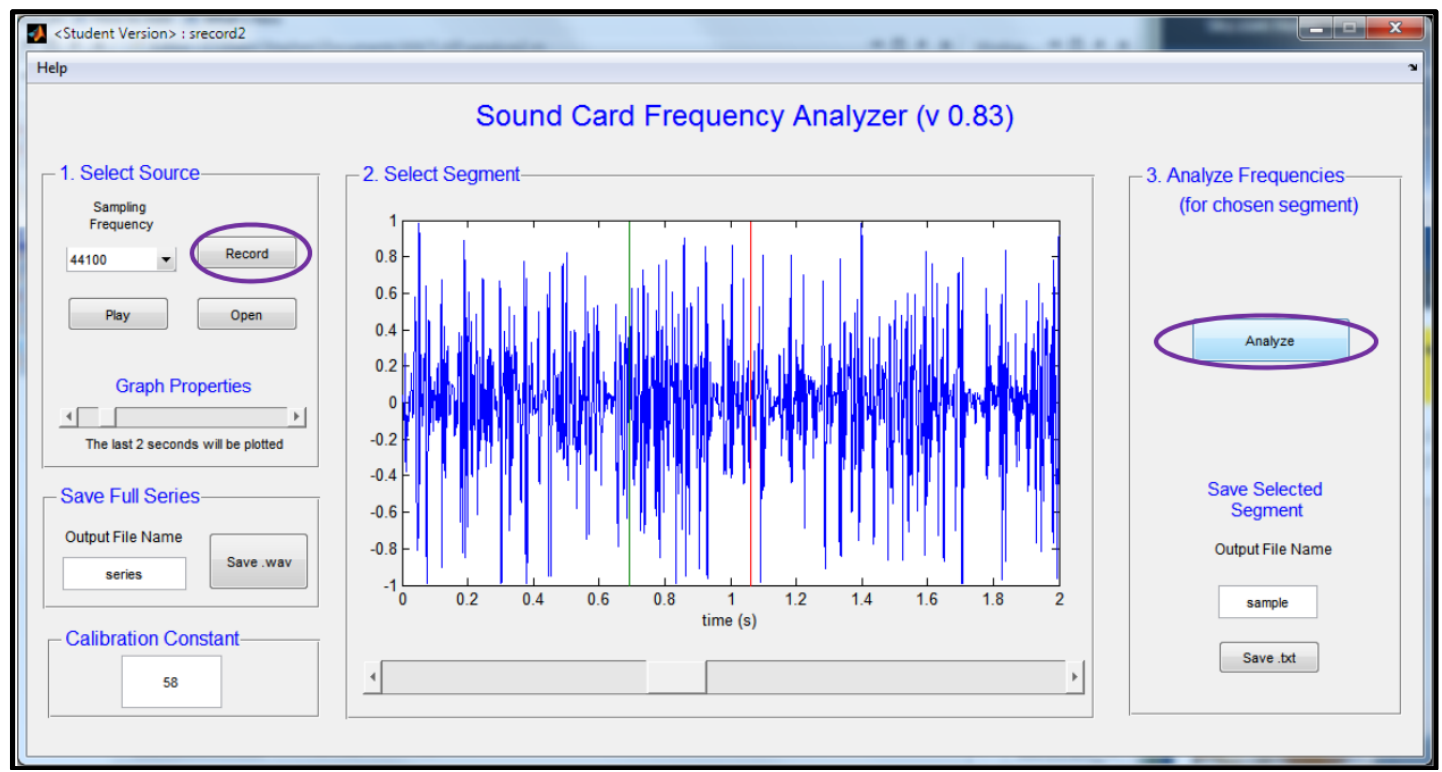

Figure 1: Sound Card Analyzer Software. The "Record" button toggles to turn recording on and off. Clicking on "Analyze” button opens a second window with a Fourier Power Spectrum, RMS voltage and a special Duty Cycle Number of the chosen segment.

The custom design of this analyzer has several advantages in scaffolding student work on the project:

1) it provides a simpler and more straight forward interface than a full oscilloscope and signal analyzer,

2) It includes a key measures of system performance (charging duty cycle, Volts RMS \& peak frequency) for this specific application that helps guide student design improvements and

3) gives students an example of what can be done in MATLAB and other programming environments.

The MATLAB sound card analyzer is more fully described in the next section. It is a key improvement to the project.

Phase III: Electrical Circuit and Final Testing - In the first week of this final phase students construct a full-wave rectification and first-order filtering circuit on a breadboard. The output of this circuit is tested using the same MATLAB signal analyzer software. Once students are satisfied with their design they connect a micro-battery to their output of their charging circuit and measure the charging of the battery over time using a multimeter. Students are asked to 
charge the battery for 30 minutes, stopping every five minutes to remove the battery and measure its charge. At the end of the projects students individually write a reflection memo.

\section{MATLAB Signal Analyzer Design}

The sound card analyzer is a simple MATLAB program with a graphical user interface. The MATLAB code (.m and .fig files) are available on the project website. ${ }^{5}$ The initial screen that opens is shown in Figure 1. It is organized into three sections based on the steps users should follow. The first section (" 1 . Select Source") allows users to choose the signal to analyze. A new signal can be recorded using the "Record" button or a previously saved signal can be loaded using the "Open" button. Once a source is loaded it appears on the graph panel in section " 2 . Select Segment." The slide underneath the graph can be used to select a portion of the recorded wave to analyze. Two lines appear on the graph showing the segment that is currently selected. The segments are a set 4096 samples long.

Once the segment is selected the analyze button in section 3 is pushed generating the graphs shown in Figure 2. This is a standard MATLAB figure window and can be edited using the usual MATLAB interactive editing tools. A time series graph and Fourier power spectrum are displayed along with three key calculations: the RMS voltage, the maximum frequency and the percent duty cycle. These graphs and values can guide student's evaluation of their design.
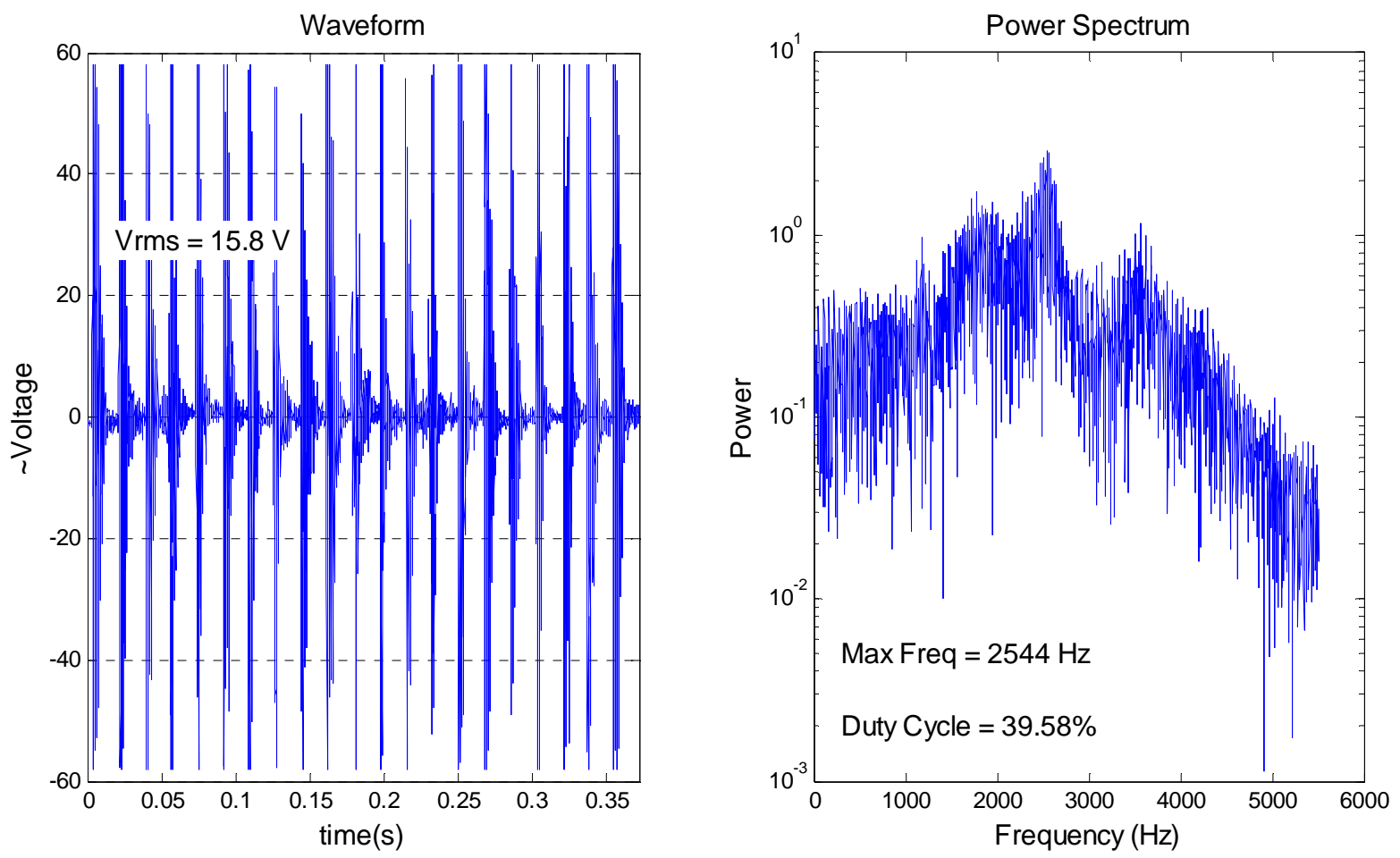

Figure 2: Graphs and measurements produced by the sound-card signal analyzer. The left graph is a simple time series of the selected portion of the signal. The right graph is the Fourier Power Spectrum for that sample. Three summary values are calculated by the program the Volts RMS, the maximum frequency and the Duty Cycle. 


\section{Charging Duty Cycle Estimate}

In order to assist the students in evaluating the quality of their design, a specialized charging duty cycle estimate is employed in the signal analyzer. For the piezoelectric signal, duty cycle was defined to be the fraction of the time that the absolute value of the voltage was above a critical threshold that was sufficient to charge the battery. This estimate helps students determine the overall "quality" of their piezobuzzer signal.

This cutoff is an estimate of the minimum acceptable charging voltage that is required from the piezobuzzer based on two factors: (1) the voltage loss that will be experienced in the charging circuit and (2) the nominal voltage of the microbattery. A loss in voltage is seen both in the full wave diode bridge rectifier and also in the ripple capacitor. Because a standard electrical diode has an activation voltage of $0.7 \mathrm{~V}$, the signal will lose approximately $1.4 \mathrm{~V}\left(0.7 \mathrm{~V}^{* 2}\right)$ due to both the positive and negative diode's activation voltage. The output of the ripple capacitor will produce a low frequency sawtooth wave which will have a certain peak to peak voltage; in order to ensure consistent charging, the peak to peak voltage of the sawtooth wave will also be added to the cutoff voltage. Finally, the nominal voltage of the battery, which is a $1.2 \mathrm{~V}$ Varta V15H microbattery, is added to the calculated cutoff voltage. This gives the following equation for minimum acceptable charging voltage:

$$
V_{\text {Cutoff }}=2 V_{\text {Diode }}+V_{\text {Ripple_P-P }}+V_{\text {Battery_Nominal }}
$$

This circuit was simulated in Multisim in order to fully evaluate its performance. The simulated circuit is shown in Figure 3 and the resulting signals are shown in Figure 4. The circuit used is a simple four diode bridge to provide full-wave rectification and a capacitor to smooth the bridge output signal. The results in Figure 4 show three traces: 1 ) the initial sine wave, 2 ) rectified sine wave, and 3) the smoothed signal after the capacitor. The ripple, peak-to-peak voltage is measured to be approximately $100 \mathrm{mV}$. Our final cutoff value for the duty cycle calculation is

$$
V_{\text {Cutoff }}=2 * 0.7 \mathrm{~V}+0.1 \mathrm{~V}+1.2 \mathrm{~V}=2.7 \mathrm{~V}
$$

The charging duty cycle is estimated to be the fraction of the sampled points where the absolute voltage is greater than this cutoff. 


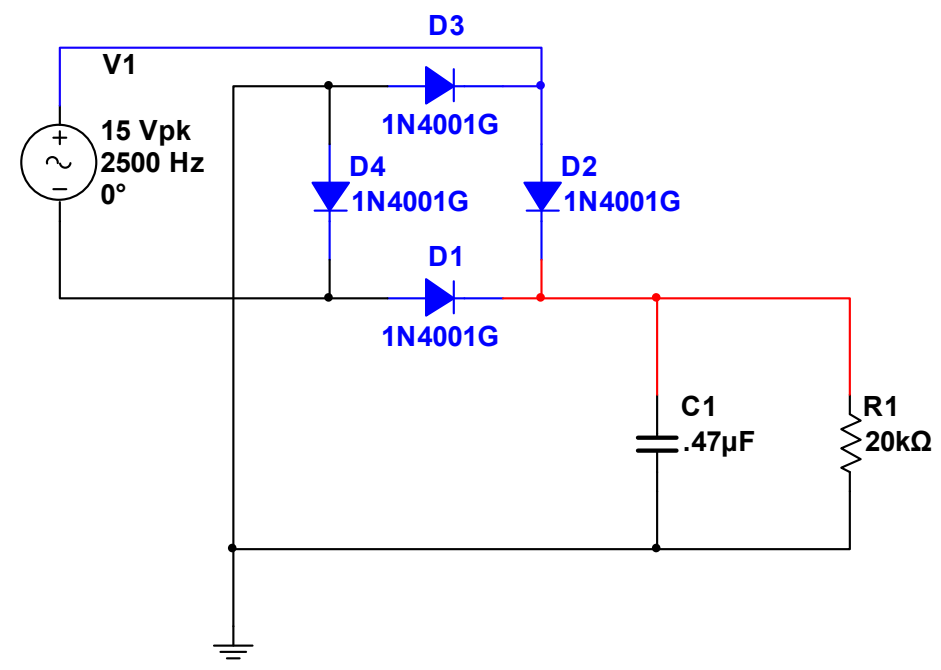

Figure 3: Simulated charging circuit. The $15 \mathrm{Vpk}$ AC source represents the piezobuzzer, which is connected to the full wave diode bridge of $1 \mathrm{~N} 4001 \mathrm{G}$ diodes. The output from the diode bridge is connected to the $0.47 \mu \mathrm{F}$ capacitor to create a nearly DC ripple voltage. A large resistor output is used in order to simulate the low current of this circuit.

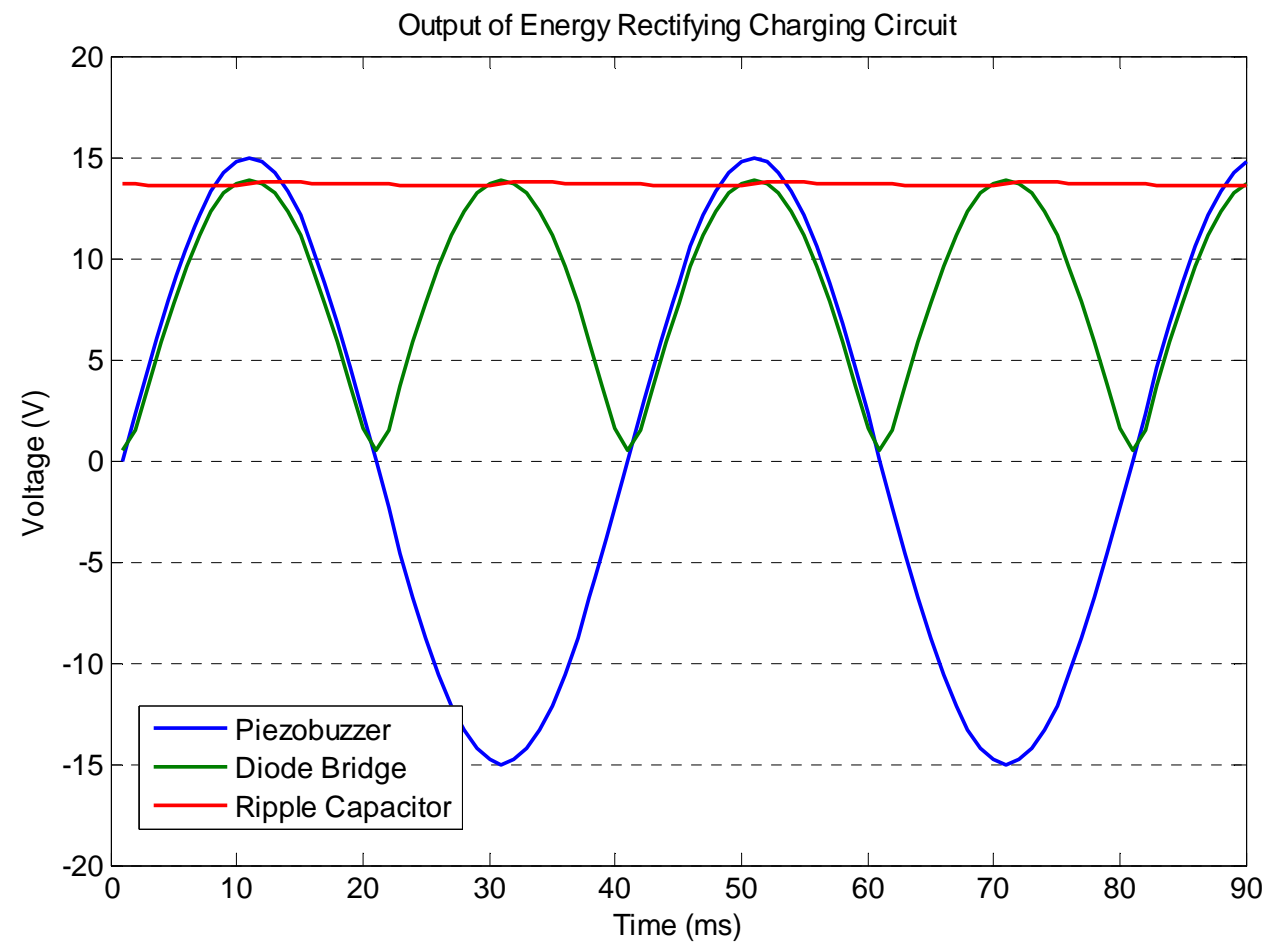

Figure 4: Charging circuit output from rectifying circuit. The blue line represents the original signal from the piezobuzzer (Ideal 15V peak @ $2500 \mathrm{~Hz}$ ). The green line is the full wave rectified signal from the diode bridge, and the red line is the output from the $0.47 \mu \mathrm{F}$ capacitor 


\section{MATLAB Signal Analyzer Performance}

The reliability of the frequency being read largely depends on the accuracy of the sound acquisition chip in the computer. To check the accuracy of the signal analyzer a RMS voltage value was set on a function generator, read by an actual oscilloscope, and then the readings of the actual oscilloscope were compared with readings from the software signal analyzer. Data from this study is shown in Figure 5. The first test was performed on a HP Z200 Workstation with a Realtek ALC262 Audio chipset. After specifying an RMS voltage output on the function generator and independently verifying the voltage on an oscilloscope, the RMS voltage was measured by the signal analyzer to determine how far off the signal was from the actual value. The calibration constant was then adjusted with trial and error to determine the correct constant. Once this was completed, the RMS Voltage was varied on the function generator and then measured again.

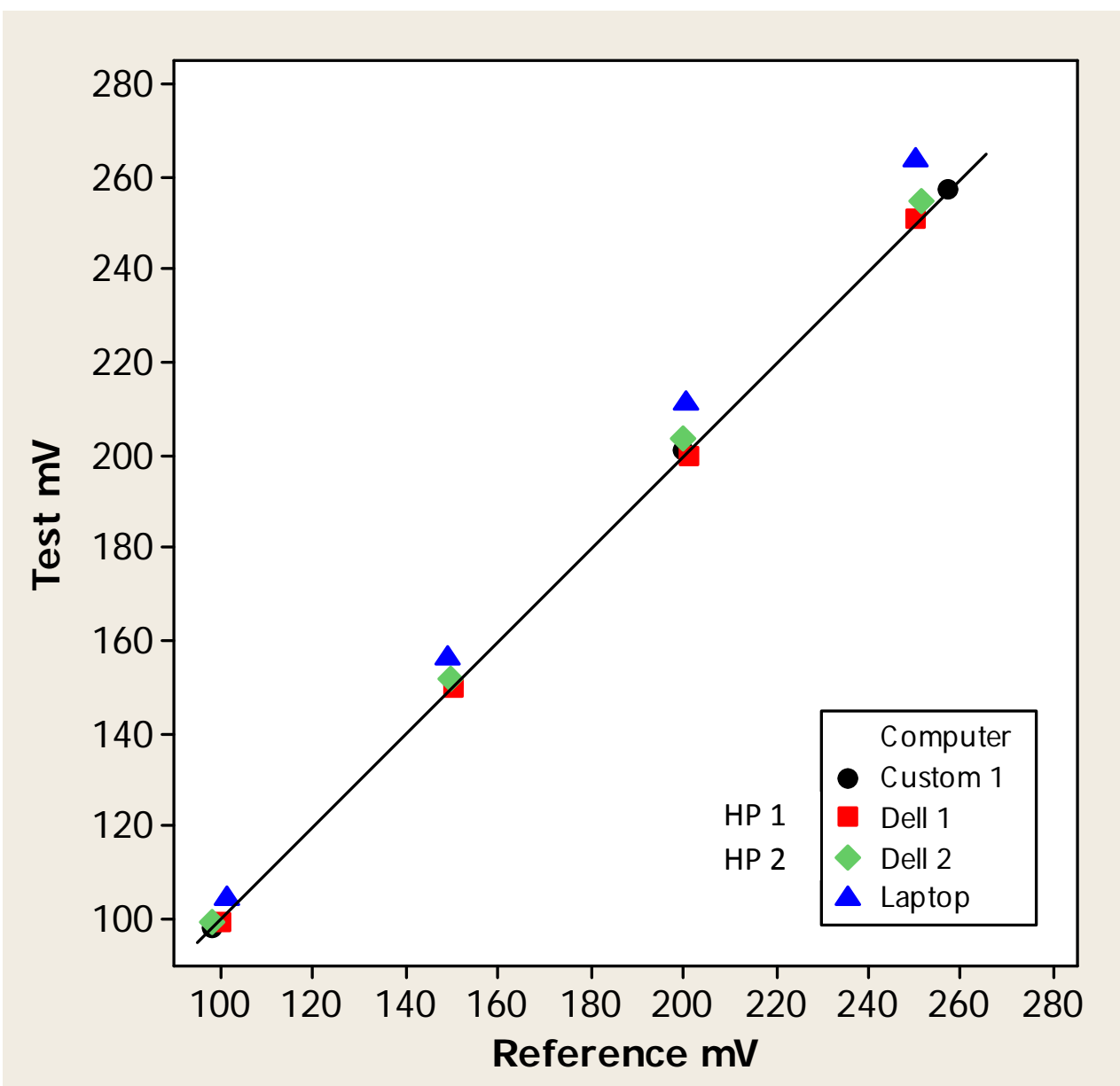

Figure 5: RMS Voltage readings for 4 separate workstations. The horizontal and vertical axes compare the actual RMS Voltage value being generated by the function generator and measured by an independent oscilloscope (Reference $\mathrm{mV}$ ) with the reading in the signal analyzer (Test $\mathrm{mV}$ ). The line plots the ideal case where the Test $\mathrm{mV}=$ Reference $\mathrm{mV}$. A different calibration constant was needed for the Custom 1 computer. The other three systems were run with the same constant. 
Once several measurements were taken, the same measurements levels were recorded using the same calibration constant on a separate computer in the lab, identical to the first computer. Without modifying the calibration constants, the readings were extremely close to the first computer. The next step was to take the same readings on an L702x Dell laptop (Intel i7 Quad Core $2.0 \mathrm{GHz}$ processor) with the same chipset manufacturer (Realtek ALC665). Again, the values were very close to the actual reading without adjusting the calibration constant. Finally, the same measurements were performed on a custom built computer with an Intel Core 2 Duo E7400 Wolfdale 2.8GHz processor. For this system a different calibration constant was needed. Once calibrated this computer consistently read the RMS Voltage values.

The testing data above also helps validate the usefulness of the software in a typical lab environment: Given a lab with a uniform computer make/model (and, subsequently, identical audio chipsets), a single calibration constant can be found using a method as above, and then using the same constant on all similar computers.

\section{Project Assessment}

One of the key goals of any project is to encourage student engagement with the course material. Strong student engagement would also be an indicator that the course goal of motivating students was being addressed. This aspect of the course was assessed using Student Course Engagement Questionnaire (SCEQ), developed by Handelsman, et.al. at the University of Colorado at Denver. ${ }^{9}$ This is a 23-question instrument that asks students about their behavior in the class. The questions scores are grouped into four engagement categories: skills engagement, emotional engagement, participation/interaction engagement, and performance engagement. These four categories are the result of a factor analysis by Handelsman, et. al. of their survey results.

Table 2 lists the survey statements by engagement category. The numbers by each statement indicate their order in the instrument. Students are asked to respond to these items with the five point Likert scale: $5=$ very characteristic of me, $4=$ characteristic of me, $3=$ moderately characteristic of me, $2=$ not really characteristic of me, and $1=$ not at all characteristic of me. Notice the instrument asks for students responses "in this course." Therefore students are responding to more than simply the project. The instrument is given to the students at the end of the term just as they are finishing the six weeks on this project; the project should figure largely but not exclusively in their responses.

Figure 6 shows the SCEQ results for the three project implementations (previous project, initial energy harvesting project and current energy harvesting project). The mean score for each of the 17 sections surveyed are shown. Means are composed of an average of 20 student instruments completed per section. An improvement can be seen in all categories between the previous project and this energy harvesting project. In addition there is a rise in average score for Skills Engagement and for Performance Engagement with the current implementation. For the other two categories the difference between the initial project implement and current implementation does not look significant. Notice for the current implementation there is one section that is particularly low. This section was the lowest in all four categories. The other two sections performance is quite strong in all categories. A clear reason for this low section has not been identified. 
Table 2: The Student Course Engagement Questionnaire (SCEQ) questions organized by engagement factors

To what extent do the following behaviors, thoughts, and feelings describe you, in this course?

\section{Skills Engagement}

4. Doing all the homework problems

5. Coming to class every day

9. Taking good notes in class

10. Looking over class notes between classes to make sure I understand the material

13. Putting forth effort

14. Being organized

17. Staying up on the readings

20. Making sure to study on a regular basis

23. Listening carefully in class

\section{Emotional Engagement}

7. Thinking about the course between class meetings

8. Finding ways to make the course interesting to me

11. Really desiring to learn the material

21. Finding ways to make the course material relevant to my life

22. Applying course material to my life

III. Participation / Interaction Engagement

2. Participating actively in small group discussions

1. Raising my hand in class

19. Helping fellow students

18. Having fun in class

3. Asking questions when I don't understand the instructor

6. Going to the professor's office hours to review assignments or tests, or to ask questions

\section{Performance Engagement}

15. Getting a good grade

16. Doing well on the tests

Table 3 summarizes the mean and standard deviation for each of these groups based on treating each student survey as an independent sample. It also shows the results of a one-way Analysis of Variance (ANOVA) for this data on the three project implementations. For all four engagement components there is a less than $5 \%$ probability that the means are equal for the three project treatments. This implies that at least some of the differences see in Figure 6 are statistically significant at the $95 \%$ confidence level. 


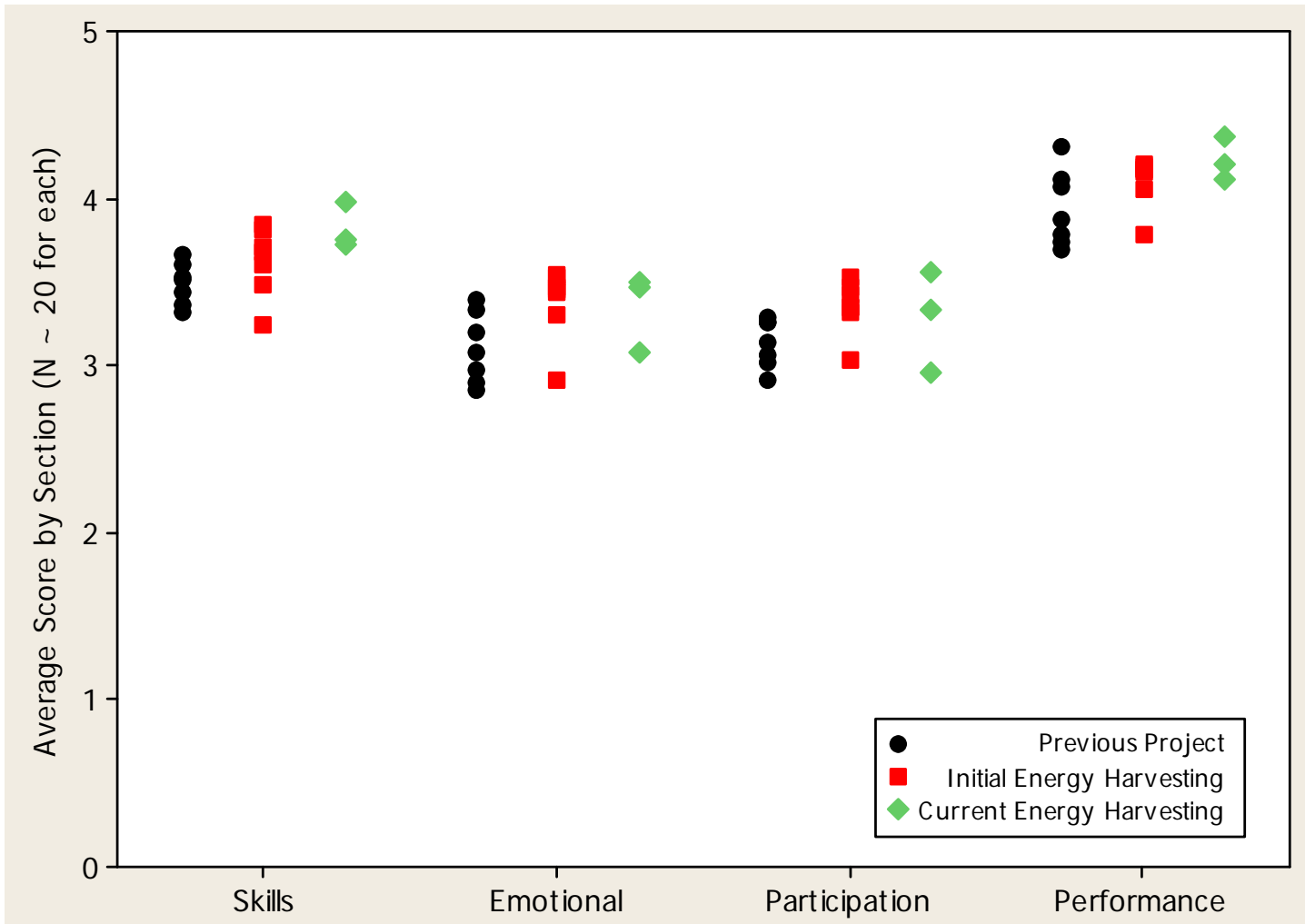

Figure 6: Average scores for class sections in each of the engagement categories. Sections are divided into the three different project situations - the previous reverse engineering project, initial implementation the harvesting project in its and its current implementation.

Table 3: Mean Engagement Scores and Variability by section for the Student Course Engagement Questionnaire

\begin{tabular}{|l|c|c|c|c|c|c|}
\hline & \multicolumn{2}{|c|}{ Number of } & \multicolumn{4}{c|}{ Mean/Standard Deviation } \\
of Student Course Engagement Components \\
\hline Project & Sections & Students & Skills & Emotional & Participation & Performance \\
\hline $\begin{array}{l}\text { Previous } \\
\text { Project }\end{array}$ & 7 & 152 & $3.49 / 0.69$ & $3.10 / 0.86$ & $3.13 / 0.69$ & $3.94 / 0.74$ \\
\hline $\begin{array}{l}\text { Initial } \\
\text { Energy } \\
\text { Harvesting }\end{array}$ & 7 & 115 & $3.62 / 0.65$ & $3.38 / 0.80$ & $3.36 / 0.66$ & $4.10 / 0.74$ \\
\hline $\begin{array}{l}\text { Current } \\
\text { Energy } \\
\text { Harvesting }\end{array}$ & 3 & 71 & $3.82 / 0.50$ & $3.35 / 0.79$ & $3.28 / 0.60$ & $4.23 / 0.52$ \\
\hline Total & 17 & 338 & & & & \\
\hline $\begin{array}{l}\text { One-Way } \\
\text { ANOVA } \\
\text { on three } \\
\text { project } \\
\text { treatments }\end{array}$ & $\begin{array}{c}\text { Pooled Standard } \\
\text { Deviation }\end{array}$ & $\begin{array}{c}\text { Probability that all } \\
\text { means are equal }\end{array}$ & 0.644 & 0.825 & 0.661 & 0.701 \\
\hline
\end{tabular}


Identifying which of the differences within an engagement category are significant is more difficult because the various differences are not independent. There are three possible differences: 1) Initial Energy Harvesting Project vs. Previous Project, 2) Current Energy Harvesting Project vs. Previous project, and 3) Current Energy Harvesting Project vs. Initial Energy Harvesting Project.

Table 4 shows the confidence intervals for a multiple comparison carried out using the TukeyKramer method. ${ }^{10}$ For each of the three comparisons above the difference between the two sample means is calculated and then a confidence interval for the difference is determined. If zero is not in the interval the difference is statistically significant. In this case, confidence intervals for each difference of means was estimated where the probability of a single false positive (type I error) for a given family of the above three differences was $5 \%$.

Table 4: Confidence Intervals for treatment differences based on Tukey-Kramer Multiple Comparison Method with a Family-wise confidence of 95\% (individual confidence intervals are 98\%).

\begin{tabular}{|c|cc|cc|cc|cc|}
\hline & \multicolumn{2}{|c|}{ Skills } & \multicolumn{2}{c|}{ Emotional } & \multicolumn{2}{c|}{ Participation } & \multicolumn{2}{c|}{ Performance } \\
\hline $\begin{array}{c}\text { Initial } \\
\text { - Previous }\end{array}$ & -0.057 & 0.3152 & 0.013 & 0.4902 & 0.0116 & 0.3938 & -0.036 & 0.3696 \\
\hline $\begin{array}{c}\text { Current } \\
\text { - Previous }\end{array}$ & 0.1121 & 0.5451 & -0.0327 & 0.5223 & -0.0665 & 0.3781 & 0.0613 & 0.5331 \\
\hline $\begin{array}{c}\text { Current } \\
\text { - Initial }\end{array}$ & -0.0278 & 0.4268 & -0.2982 & 0.2846 & -0.2804 & 0.1866 & -0.1172 & 0.378 \\
\hline
\end{tabular}

This approach to multiple comparisons is relatively conservative. The intervals in Table 4, which are significant at this level, are highlighted in green. The intervals highlighted in yellow just barely include zero and would be significant at the $90 \%$ level for the family-wise error (and at the $96 \%$ level for the individual confidence intervals). This table shows some clear improvement for the energy harvesting project over the previous project. The current implementation shows significant improvements in Skills and Performance Engagement. The initial implementation of the energy harvesting project shows significant improvement for Emotional and Participation/Interaction Engagement.

Overall, these results do indicate a clear improvement over the previous project. They indicate similar or better results over the earlier implementation of the project in the course. It is possible that some of the rise in particularly the Skills Engagement category is due to improves in other parts of the course as well as the improvements to this project.

The rise in the Performance Engagement category likely reflects an improvement in the students' confidence and could be a result of the additional scaffolding added to the project. The Performance Engagement category made up of the fewest items (only three statements are included) and one of these items is not actually relevant to the course. This item asks about their doing well on tests and there are none in this particularly course. However, student responses in all three items where consistently high indicating confidence that were able to handle the course 
and project material.

Instructor observations: Overall the instructors did observed an improvement in the quality of student designs and better student satisfaction with the results of their design process. The structured steps seems to help students progress through their project and particularly the two stage design assignments (conceptual design and implementation) with a discussion in between resulted in better initial student designs.

The addition of the custom designed MATLAB sound-card signal analyzer allowed both students and instructors to focus on the design problems rather than getting side tracked with a more complex instrument than necessary for this initial project. The incorporation of the duty cycle measurement in this scope drove students toward better design decisions and more realistic expectation of the final design's performance charging a battery. Prior to implementing this measure students tended to prefer very large voltage peaks but did not pay attention to how frequent those peaks where.

\section{Conclusions}

This project is accessible and engaging to first-year students as well as being practical and economic to implement. Results of the SCEQ instrument show improved student confidence and skills with this project and its development. The use of a staged design process, with an initial open-ended conceptualization phase, a class discussion of design options and a final design implementation, seems to be successful at producing better designs while maintaining an independent design conceptualization by the students. A similar staged design approach could easily be used with a range of other student design projects.

The sound card software is one of the keys to this project. It helps the students understand the concepts being taught without getting bogged down in learning a full oscilloscope interface. The software calculated duty cycle estimate effectively predicts the charging capability of their design. This allows the students to test and modify their ideas quickly. This parameter encourages students toward better designs.

This sound card software also has implications and applications beyond this project. The analyzer is readily available via a web site and easily adapted to other specific projects that need the data logging and frequency analysis of a low voltage signal. In addition, the general concept of using software instruments custom designed for first-year projects has broad possibilities. There is a broad range of inexpensive hardware and software available to first-year programs today. These products make it practical to implement custom computer-based instruments that can help scaffold student learning.

Key goals of this project were to be engaging to students, to develop skills and habits of a disciplined engineering process, to be informed about a range of engineering topics, and to be practical to implement. The SCEQ results indicate solid engagement in multiple categories. The staged process structures an example of a simple but disciplined engineering project process. This energy scavenging project incorporates mechanical, electrical, and software elements and introduces a range of soft skills including teamwork, communication, design process, and 
experimentation. Finally this is a very practical project. By using LEGOs ${ }^{\circledR}$ for the mechanical assemblies and solderless breadboards for the electrical assemblies, students can easily design

and redesign their systems without excessive cost or build time. The CAD software used for the LEGO ${ }^{\circledR}$ designs is free and the oscilloscope/measurement software is written in MATLAB, software that many universities already possess.

\section{Acknowledgement:}

We would like to thank Dr. James Isaacs for his help developing the Multisim model of the rectifier circuit.

\section{Bibliography}

1. Reid, K., Hertenstein, T., Fennell, G. and Reeping, D., "Development of a First-year Engineering Classification Scheme,” 2013 ASEE Annual Conference and Exhibition, Atlanta, GA, June 2013 .

2. C. Cossio, "Harvest energy using a piezoelectric buzzer,” EDN, pg.94-96, March 20, 2008

3. Y. Liu and C. Pomalaza-Ráez, "Freshman Engineering Project on Energy Scavenging," International Journal of Engineering Education. Vol. 27, No. 5, pp. 1061-1071, 2011.

4. Litzinger, A. L., L. R. Lattuca, R. G. Hadgraft, and W. C. Newstetter, "Engineering Education and the Development of Expertise,” Journal of Engineering Education, 100 (1) pp. 123-150, January 2011.

5. Moor,S, Resources for Energy Scavenging - an Introductory Engineering Project, http://engr.ipfw.edu/ moor/EScavenging/, March 2014.

6. Michael Lachmann, MLCAD - Mike’s LEGO® CAD, n.d., http://mlcad.lm-software.com/, accessed October 2013.

7. Atman, C. J., R. S. Adams, M. E. Cardella, J. Turns, S. Mosborg, and J. Saleem, “Engineering Design Process: A Comparison of Students and Expert Practitioners,” Journal of Engineering Education, 96(4), October 2007.

8. Holtzapple and Reece, Foundations of Engineering $2^{\text {nd }}$ Ed., McGraw-Hill (2002).

9. Handelsman, M. M., W. L. Briggs, N. Sullivan, A. Towler, “A Measure of College Student Course Engagement,” The Journal of Educational Research, 98(3), pp. 184-191, (2005).

10. Rafter, J. A., M. L. Abell, and J. P. Braselton, “Multiple Comparison Methods for Means,” Society for Industrial and Applied Mathematics (SIAM) Review, Vol. 44, No. 2, pp. 259-278 (2002). 